\title{
Are Our Emotions True Cognitions?
}

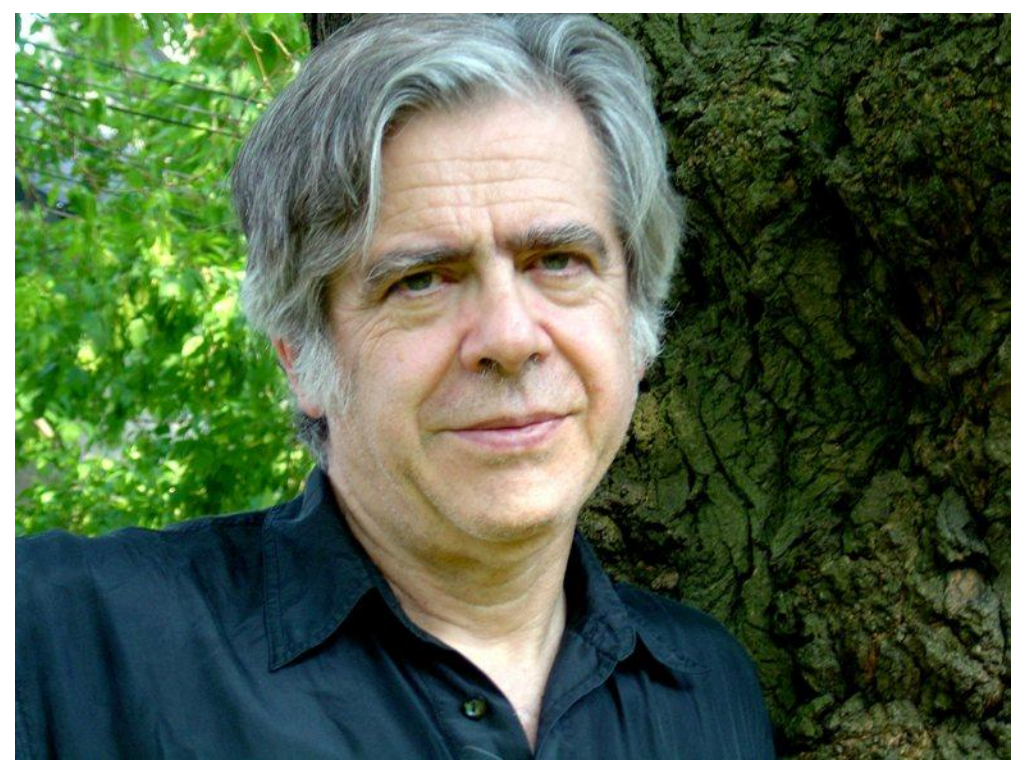

Ronald Bon de Sousa Pernes (born 1940 in Switzerland) is an Emeritus Professor at the Department of Philosophy of the University of Toronto which he joined in 1966. He is best known for his work in philosophy of emotions, and has also made contributions to philosophy of mind and philosophy of biology. He was elected a fellow of the Royal Society of Canada in 2005. De Sousa possesses both UK and Canadian citizenship. Educated in Switzerland and England, he took his B.A. at New College, Oxford University in 1962, and his Ph.D. at Princeton University in 1966. He has contributed to and is frequently cited in the Stanford Encyclopedia of Philosophy.

Andrzej Dabrowski: Philosophy is the systematic study of world, human being, knowledge, mind, thinking, rationality. The affective life is not the most important subject of philosophy. First existentialism and philosophical anthropology have established philosophical interests in human emotions. You are working in philosophy of emotions. How did you first become interested in this subject? Why emotions? And what are the differences between the modern emotion philosophy and Max Scheler and Jean-Paul Sartre's first ideas?

Ronald de Sousa: I'm not sure that existentialism and philosophical anthropology can be credited with "first establishing" the philosophical interest in emotions. Historical figures such Plato, Aristotle, Spinoza, Descartes, Hume and William James, to name just some of the major names in the philosophical canon, were all very interested in emotions. But it is certainly true that in analytic philosophy as well as in psychology emotion theory suffered a hiatus for most of the first half of the 20th century. In psychology, that can probably be attributed to the dominant influence of behaviorism; in philosophy, to the primacy of linguistic philosophy. Emotions seemed just too complicated to tackle from the perspectives of those research programs. The study of emotions requires multiple points of view and emotions themselves touch on many areas of philosophy. My own preferred view of philosophy is as a license to be a dilettante; so it is perhaps precisely because I was reluctant to specialize in any narrow branch of philosophy that I became interested in emotions. For they seemed to constitute a domain on which many of my interests could converge: my original specialization of the philosophy of language (in which I wrote my doctoral thesis), and my interests in epistemology, in ethics, in aesthetics, in literature and, of course, in the philosophy of mind. Emotions raise problems in all these areas. For the philosopher of language, the different 
senses in which emotions have "objects" demand that we understand what Donald Davidson called the "variable polyadicity" of events in general and mental representational states in particular. Whether emotions bring us knowledge of the external world, of ourselves, or of both, is a question that concerns both epistemology and the philosophy of mind. Emotions play a crucial role - though certainly not an uncontroversial one - in ethics and aesthetics. And since literature is the richest source of available discourse about emotions, that provides a philosopher of the emotions with a good excuse to spend time reading fiction and poetry. Max Scheler's chief contribution to the theory of emotion was to emphasize their role in our apprehension of values. This highlights their relevance to both epistemology and the theory of value - both ethical and aesthetic. It is probably fair to say that contemporary philosophy of emotion, my own in particular, is more hesitant to posit an objective realm of value to which emotions provide epistemic access; I myself am more inclined to think of values as projections of emotions; in practice, however, I'm not sure that this makes a great deal of difference. As for Sartre, I associate him with two ideas, both of which are intriguing but ultimately unconvincing. The first, which was much emphasized by Robert Solomon in his early work on emotions, is that emotional responses are a form of magical thinking, producing unreal solutions to insoluble problems. The second is that we are as much responsible for our emotions as for any voluntary choice. What is wrong with the first idea is apparent as soon as we think of the importance of emotions to us as evolved animals: the biological perspective makes it immediately implausible that a phenomenon as important to our lives as emotion should be devoid of efficient practical utility. Although emotions cause us much trouble, in the main, they represent swift solutions to certain authentic problems that arise from ordinary human situations. As for the other idea promoted by Sartre, it certainly serves as a useful reminder of the fact that we need not be helpless victims of purely passive emotions: emotions can be thought through, emotional responses are often the result of ideological commitments and prejudices which philosophical thinking can overcome.

Andrzej Dabrowski: Above you mentioned the philosophy of mind. The concept of modularity has played an important role in recent debates in the philosophy of mind. Are emotions modular?

Ronald de Sousa: Emotions 'mimic' the modularity of perception. That is what I meant by saying that they spare us the Frame Problem. But whether they ARE modular is another and rather complicated question. Since I am on record with a paper called Against Emotional Modularity (which goes into this in more detail than I can rehearse here), I have to watch what I say. Or at least re-read what I did say... The word is used in a number of ways. In Fodor's book on The Modularity of Mind it had a very specific meaning, and applied to the informational encapsulation (the inability to respond to other channels of information, including beliefs) of our senses. Thus we do not dispel the Muller-Leyer illusion even when we know it to be an illusion. It is in this sense that emotions mimic modularity. They are not really modular in the original sense, because unlike sight or hearing, we are not stuck with the separation of channels in perpetuity. When the emotion has subsided, it can allow the person to see other points of view. (Providing the person is willing to allow it: a question of emotional maturity, or perhaps "intelligence", though that is another controverted term). So, emotions are not literally modular in that sense. In the more recent literature (including most of the papers in a volume edited by Faucher and Tappolet, The Modularity of Emotions, 2006, to which the article I mentioned above was my contribution), modularity is interpreted as some sort of evolutionarily programmed unit of complex responses designed to deal with some stock situation type. It applies to the "basic" emotions, for those who recognize such things. In this guise, emotions belong to the fast, automatic, low-effort, inexplicit mode of processing identified in the 'two track mind' or what is usually called 'dual processing', as opposed to the deliberate, usually language-based, attention-hungry, 'second track' processing. In that sense, modularity can be understood as implicating something like one of Griffiths' "affect programs", not merely selected but selected for by natural selection; or else it can identify emotions as clusters of 
more basic responses varying in a number of dimensions of concern. For my part, I like to stress another aspect of this question - in effect, another sense of modularity. That is the rigidity of the categories in terms of which we understand and classify emotions. The need for such simplified categorization arises from our need to talk about emotions. But the categories in question are far from adequate to render the subjective experience of emotion. That is why some of our emotions are sometimes said to be 'ineffable'. More subtle emotional experiences are vital to all aesthetic experience, and it seems to me vitally important, in order to allow for our full potential for apprehending the aesthetic aspect of our real everyday life, that we should try to free the reality of our multifarious emotional experience from the constraints of rigid categorization.

Andrzej Dabrowski: Whether human emotions have changed historically? Many scientists (philosophers also like P. Griffths) believe that historical studies contribute nothing to the study of emotions. Do you agree with those researchers?

Ronald de Sousa: I do think emotions have changed historically as ideologies governing interpersonal relations, both public and private, have changed. Some of the virtues identified by Aristotle, in terms of their emotional stance to such things as honor, derived from specific forms of aristocratic values. Without subscribing to Nietzsche's conception of a complete inversion of those aristocratic values under the influence of Christianity, the general lesson that we can retain from Nietzsche is that the genealogy of morals affects their essence, and that emotional stances towards values promoted by warrior societies, say, or in the context of capitalist economies, can be very different from one another. I am not sure what psychologists you allude to when you suggest that many of them think historical studies have nothing to contribute to the study of emotions. The International Society for Research in Emotion (ISRE), and the largest collaborative research institution I know of, the Centre for the Interdisciplinary Study of Affective Science (CISA, in Geneva), for example, both make a point of including historical studies in their overall research plans. My interpretation of Paul Griffiths' view is that he thinks only biologically innate "affective programs", of the sort associated with short lists of basic emotions, can be regarded as forming psychological natural kinds exemplifying homologies with dispositions observed in other primates or mammals; but as I understand him he does not deny that many of the phenomena we call emotions may form complex, socially constructed clusters of response dispositions that have their own psychological reality and sociological significance. That is certainly my view. Moreover confidence in the existence of "basic emotions" has waned in recent years; a more thoroughly constructionist view might appeal to even more basic processes in the construction of what I have called "paradigm scenarios" which define different specific emotions. But that would render them all the more susceptible to alteration on the basis of changes in ideological assumption about what is "normal" or "expected" in a given social context.

Andrzej Dabrowski: Are cognitions and emotions one or two different worlds? The first books on cognitive psychology and cognitive sciences as such had no chapters on emotions. The situation has recently changed. There are a huge number of books devoted to close connections between emotions and cognitions. Even there was a cognition-emotion debate. Are there any significant philosophical results of this debate?

Ronald de Sousa: The cognitive science revolution, perhaps beginning with Chomsky's notorious review of Skinner's book on Verbal Behaviour, was certainly more interested, at first, in belief formation, inference strategies, and memory. But it soon became clear to pretty much every one concerned that emotions played a crucial part in those cognitive processes, both for good and ill. Several scholars have noted the existence of specifically epistemic emotions such as interest, doubt, and the feeling of certainty. Again, these are not really new, since they figure prominently in both Plato's Meno and The Meditations of Descartes. The precise way in which emotions contribute to 
cognition is indeed, as you say, an active area of current investigation. A very interesting recent book by Michael Brady, for example, argues that emotions do not directly afford a knowledge of axiological facts, but rather provide us with motivation for looking into evidence for such facts. Thus fear does not give us evidence for thinking something is dangerous, but does provide a motive for paying attention to what might be a threat. The intertwining of emotion and cognition in current philosophy and psychology is itself, in my view, an important philosophical result. One of the manifestation of the interaction of cognition and emotion is the growing interest shown in "affective computing" by scientists working in Artificial Intelligence. From the philosophical point of view, I would stress the crucial role of emotions in complementing mere logical inference in two essential ways: first, our emotional states set or at least constrain our goals. Emotions therefore set the stage for any rational calculation. Second, by narrowing the field of our attention to immediately relevant concerns, emotions, I have suggested, largely save us from the "philosopher's frame problem". That problem, originally identified as a difficulty for computer science, lies in the importance of knowing what to ignore among the myriad possible consequences of any action. Since it is in practice impossible to give adequate consideration to all of those possible consequences, our narrowing of attentional focus under the influence of emotion allows us to concentrate on only subsets of potential consequences of whatever we undertake.

Andrzej Dabrowski: Physiological (or somatic) theories of emotion (W. James, R. Zajonc, A. Damasio, J.E. LeDoux, J. Prinz) claim that bodily responses are essential to emotions. Defenders of cognitive theories of emotion (W. Lyons, R. Solomon, M. Nussbaum, J. Neu) argue that cognitive elements - beliefs, judgments, evaluations, or thoughts - are essential to emotions. Is there a chance to reconcile (to unite) these two different perspectives?

Ronald de Sousa: I don't really see much of a conflict. Those who are interested in the physiology of emotions focus on the so-called basic emotions that have homologues in other primates, such as fear, anger, joy and sadness. Insofar as those involve rather primitive responses, they are not, in my sense, yet fully emotions, but rather proto-emotions. Most emotion researchers acknowledge that a full-fledged emotion unites cognitive, experiential, physiological, expressive and conative (or "action tendency") components. The complexity generated by that combination, and the modulation of the physiological elements by thoughts, make for elaborate human emotions that are characterized by a dramatic structure ("paradigm scenarios"). Those thought-driven emotions are, to some degree, susceptible to "re-gestalting": meaning that one can construe a situation in different ways by thinking about it in a new way. Thus, for example, anger might be turned to compassion if one construes offensive behavior as resulting from discomfort or ineptitude rather than hostility. In her book The Managed Heart, Arlie Hochschild relates that flight attendants were trained to cope with drunken and irate passengers by gestalting them as babies having a tantrum. The more thoughtimpregnated emotions are obviously the most interesting from the philosophical point of view. But there is no problem of reconciliation with more basic emotions: unlike Griffiths, I regard all of them as emotions, but I agree with him in seeing them as belonging to significantly different classes.

Andrzej Dabrowski: Do you think your theory (or proto-theory?) on the rationality of emotions presented first in The Rationality of Emotion (1987) seriously evolved?

Ronald de Sousa: From my 1987 work, I still retain a number of convictions. First, that in individual human lives each of us forms a repertoire of emotions that is to some extent idiosyncratic. We each have our own "emotional idiolect". These idiolects, like literal idiolects in language, are constructed relatively early in life, out of a stock of basic human capacities to respond; these are integrated into paradigm scenarios in terms of which we interpret subsequent episodes of our emotional life. 
Art, literature, and philosophical reflection are all able to modify those scenarios to some extent; but the tendency to exhibit repetitive patterns that characterizes most people's emotional biography bears witness to the tenacity of the original scenarios as well as underlying temperament. I also still think that the idea of pure rationality makes no sense without the double role of emotions in setting the questions to which we seek rational answers, and the narrowing of our attention so as to constrain the range of relevant considerations that we bring to the search for such answers. Both roles, of course, can work against us on occasion (all virtue is vice, though not vice versa!). The counter-productive nature of many familiar emotions (anger, jealousy, spite) illustrates the way in which the "blinders" imposed by our emotional states can cause us to miss what from a broader point of view might turn out to be the most important things. In my work since The Rationality of Emotion, the main change in my perspective is that I have come to think that many of the problems raised by the theory of emotions are illuminated by the relation between the two "levels of processing" mentioned above. Emotions straddle the intuitive and the analytic tracks, which is why it is worth regarding them as having functional aspects in common despite the difference between Griffiths' strictly defined "affect programs" and what he calls the "cognitive emotions". I have not been concerned so much with modifying those ideas, but in seeing how they can be applied to a range of issues of more general philosophical interest. On the theoretical level, these include a more elaborate notion of "generic truth" which can make sense of the ascription of truth to emotions, and I have tried to take a broader view of what we may count as 'cognitive' than the once dominant emphasis on propositional objects. On the practical implications of emotion theory, I have come to regard emotions as crucially significant for ethics and aesthetics. I have also been interested in more specific problems arising from a philosophical perspective on the pursuit of happiness, on love, and on the possibility of taking a more richly aesthetic attitude to our own emotional lives. These issues form some of the topics in Emotional Truth (2011). More specifically, I have recently focused on love, which I regard not as an emotion like others but as a syndrome. By that term, I refer to a peculiar feature that distinguishes love from other emotions (though in some cases it is a matter of degree), namely that any emotion at all might be, in some context, a manifestation of love. The role played by ideology in defining what we think of as appropriate feelings, behaviour and attitudes in love is the focus of my most recent book, Love: A Very Short Introduction, which takes aim at some of the absurdities and hypocrisies that pervade most people's endorsement of the ideal of monogamous marriage.

Andrzej Dąbrowski: It's an interesting topic. There were many attempts to find the equation of love... Maybe did you do it? What the value of love is?

Ronald de Sousa: I'm not quite sure what you have in mind by the 'equation' of love. As I mentioned, love is not so much an emotion as a 'syndrome'. (This is a view that has now been elaborated in a superb paper by Arina Pismenny and Jesse Prinz, to appear in an Öxford Companion to Love and Sex edited by Chris Grau and Aaron Smuts.) Perhaps, indeed, love should be said to be several different and perhaps even incompatible syndromes. What I find most striking when thinking about love is that although the various sorts of human affiliation that go by that name obviously have deep biological roots, they are strongly influenced by expectations that stem from ideology. Current ideology in the Western world insists, for example, that passion, sexuality, companionship and intimacy are all essential to love, and that all of these must form a psychological conduit to monogamous marriage. But in reality those ways of connecting are very different in their character and particularly in their typical duration. So in real life they fall out of step, leading to bitter disappointments and resentments rooted in unrealistic expectations. In a modern world where we no longer have to associate sex with reproduction, and where rigid social rules no longer require that everybody's life should follow one of a few set patterns of affiliation, the ideal of monogamous marriage (which at best was 'honoured more in the breach than in the observance') could be and is being re-thought more realistically. Such re-thinking, and the 
experiments in living carried out by polyamorous communities, aim at allowing those different components (passion, companionship, and specific goals such as the raising of children) to be pursued in relative independence of one another. They are premised on the curiously unpopular notion that pleasure is not intrinsically sinful, and that emotional authenticity and fidelity need not be defined in terms of sexual or affectionate exclusiveness. In this way, philosophical investigations of love bring the practice of philosophy back to its ancient connection with the quest for better ways to be human. 